\title{
Two Operative Risk Indicators as Tools for Negotiating Contracts Between Curators of Museums and HVAC Technical Services Providers
}

\author{
Laura Cirrincione ${ }^{\mathrm{a}, *}$, Antonino Nucara ${ }^{\mathrm{b}}$, Giorgia Peri ${ }^{\mathrm{a}}$, Gianfranco Rizzo ${ }^{\mathrm{a}}$, Gianluca \\ Scaccianoce ${ }^{a, c}$ \\ a Department of Engineering, University of Palermo, Viale delle Scienze Bld. 9 Palermo, Italy \\ b Dipartimento di Ingegneria Civile, dell'Energia, dell'Ambiente e dei Materiali, Università \\ Mediterranea di Reggio Calabria, Italy \\ ${ }^{c}$ National Research Council of Italy, Institute of Biomedicine and Molecular Immunology, \\ via Ugo La Malfa 153, 90146 Palermo, Italy.

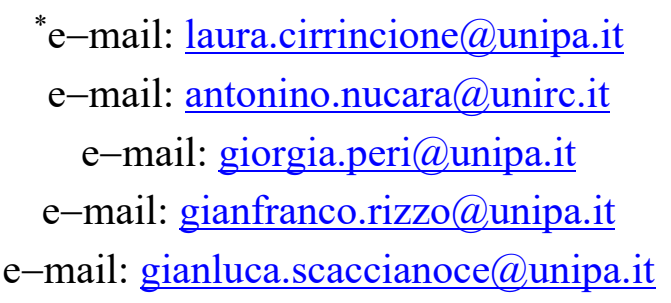

\section{ABSTRACT}

The purpose of Heating, Ventilating and Air-Conditioning (HVAC) systems in museums is to properly control important microclimate parameters; such systems, in fact, apart from ensuring the visitors' wellbeing, are requested to guarantee suitable indoor conditions for the proper conservation of the important cultural goods hosted by museums. Hence, in case of disservice, or interruption due to maintenance interventions, it is important to quantify the economic damage induced to exhibited and/or stored works of art (or even to the building museum itself). Accordingly, it is essential to guarantee the shortest possible period of disservice during which probable damages for the works of art could occur.

Since curators are the most relevant subjects committed to properly run the museum, also for what concerns the indoor environmental conditions, the aim of this work is to propose two new comprehensive operative damage risk indicators to support curators in negotiating the stipulation of contracts with the external companies in charge of the management of the HVAC system, in order to preserve the works of art. Particularly, these indicators try to integrate, into the contracts, economic considerations related to the system's disservice period and/or planned interruptions.

The feasibility of the proposed new indicators has been checked by means of an example application involving the "Museo Regionale" of Palermo (Italy).

\section{KEYWORDS}

Works of art preservation - Risk Indexes - Environmental conditions - Museums - HVAC management and maintenance service contract - Economic cost.

${ }^{*}$ Corresponding author - E-mail address: laura.cirrincione@unipa.it 


\section{INTRODUCTION}

The purpose of Heating, Ventilating and Air-Conditioning (HVAC) systems is to properly control important microclimate physical parameters: such role is even more important in museums, since both the visitors' wellbeing and the preservation of works of art must be addressed [1, 2]. Particularly, in case of historical buildings, when considering strategies and technologies to adopt in order to optimize their energy performance [3, 4], the aspect regarding the compatibility between providing appropriate thermal performances and maintaining the architectural integrity of the building must be considered $[5,6]$.

It must be noted that the above-cited requirements can be sometimes controversial, since the environmental conditions required to preserve the artefacts could not be able to guarantee people comfort at the same time [7,8]; this issue constitutes one of the main threats to which museum collections are subjected to (i.e. inappropriate environmental conditions), when the wellbeing of visitors is put first $[9,10]$. In this regard, the methods to be used for monitoring and characterizing the environmental air quality inside museums, with the aim of singling out possible common ranges for the microclimate conditions, should also be clear, easy to apply and not too invasive in order not to interfere with the visual scene $[11,12,13]$.

As for the HVAC systems, other than the planned interruptions due to maintenance operations, accidentally undesired failures, causing an unwanted delay of the planned interruption times, may occur. Such drawbacks could determine unsuitable indoor microclimate conditions, with possible thermal discomfort for the museum visitors, and, most importantly, they could result in unsuitable microclimate conditions for the exhibited works of art, which could determine damages to them [14, 15]. Furthermore, different works of art (characterized by different internal parameters related to the diverse materials) generally require different environmental conditions for their proper preservation, which makes the management and control of the indoor thermal microclimate even more difficult $[16,17]$.

An Italian standard [18] states that curators must take the final decision regarding the setting of the proper environmental physical indoor parameters for the items exhibited in galleries and museums; in fact, the most suitable microclimatic conditions strongly depend on the history of the item itself, which the curator usually knows well. People responsible for the general running of museums (such curators indeed) are the ones called to assess effective strategies that, among other features, could limit an too frequent interruption of the HVAC system. Therefore, they must draw up suitable contracts to regulate properly the relationships with the companies in charge of the management of the museum's HVAC system [19, 20]. Specifically, the objective of a proper management of a HVAC system, other than providing a sound, energy efficient and cost-effective functioning, is to ensure the compliance with the in-force standards and regulations regarding both the comfort, health, and safety of building occupants, and the works of art preservation [21, 22].

Moreover, considering that about $40 \%$ of all non-residential buildings (of which museums are part) contract maintenance service for HVAC equipment, and as third-party providers become more sophisticated in selling services, building managers (such as, indeed, museums curators) need to become better-informed consumers [23].

Based on the above cited considerations, the evaluation of the physical parameters inside museums should consist not only in verifying the respect of the tolerance intervals for the 
preservation of the artefacts, but also in taking into account the probability with which a HVAC system malfunctioning (i.e. time during which these parameters fall outside the optimal range) may occur, which in turn could result in a risk for the artefacts themselves.

In fact, as confirmed by the previously cited literature, the relevance of risks related to the HVAC systems' disservice period is associated to their maintenance and management operations. Hence, to be effective, also from the economical point of view, an optimal maintenance and management planning should require the right combination of managerial and technical skills [24].

\section{RESEARCH AIM}

This work intends to provide a tool to support curators in the stipulation of contracts with external companies ("Global Service", for instance) in charge of the management and maintenance of the HVAC systems installed in their museums, in order of optimizing the preservation of the artefacts. To accomplish this task, two new operational indicators (called $O P_{1}$ and $O P_{2}$ respectively), taking into account the technological/engineering aspect of the problem, are proposed here, which are intended as a support tool for curators to properly evaluate the planned interruptions for maintenance operations of the HVAC systems and to establish the maximum duration of acceptable disservice, also on the basis of economic operative considerations. The relevance of risks is, in fact, related to the HVAC system disservice period, that is when the system is not able to maintain assigned environmental conditions related to pre-set reference values.

Figure 1 shows the logical process at the base of the work carried out in this paper, with the framing of our proposal (squared in red) in the context of the above-described issue.

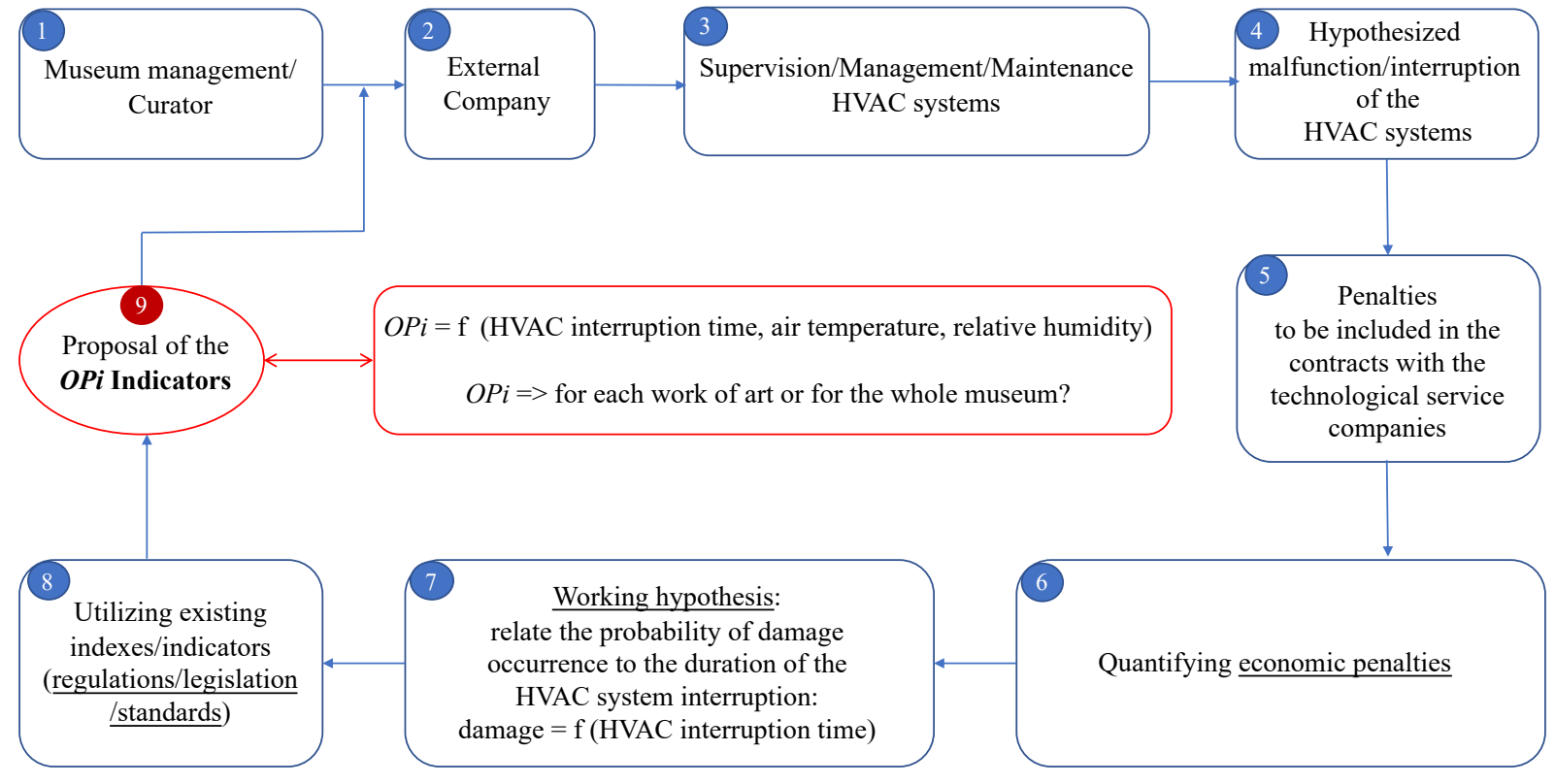

Figure 1. General framing of the present proposal.

As observed in Figure 1, the proposed indicators are based on indices and indicators already present in literature. Furthermore, an investigation into the feasibility of the two comprehensive 
and operational indicators has been carried out through a case study, which involved the "Museo Regionale" of Palermo (Italy).

Before introducing the two new indicators, $O P_{1}$ and $O P_{2}$, a description of both the logical procedure that guided us in the development of these indicators, and of the already existing literature indoor performance indexes, is provided below.

\section{METHODS AND MATERIALS}

\subsection{The logic behind the development of a comprehensive and operative damage risk indicator}

An eventual risk for the works of art is related to the total duration of the period during which the indoor physical parameters are higher or lower than the given limits established by the technical standards in force (Figure 2). Therefore, the probability of damage for the works of art could be reasonably related to such possible dangerous events. This should lead to an indicator dependant on monitored physical parameters on which the risk is suggested to depend.

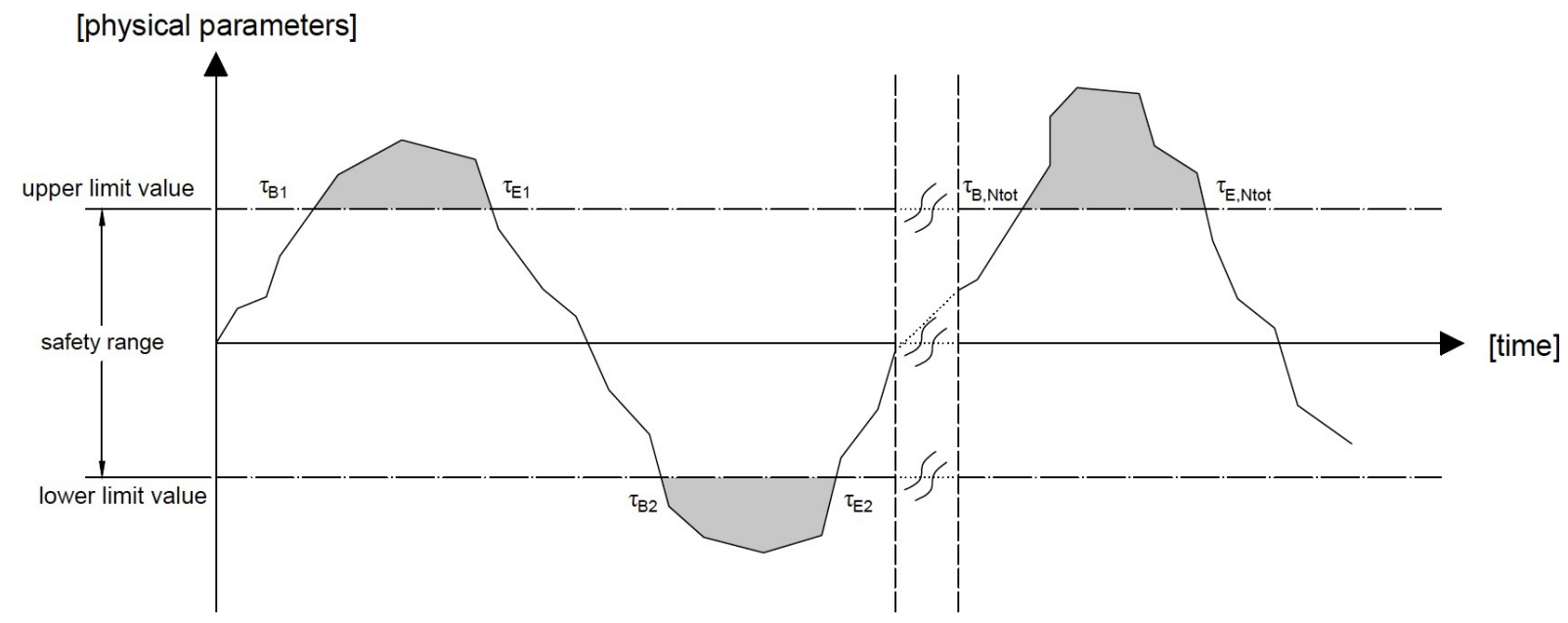

Figure 2. Graphical representation of the eventual risk conditions for the works of art.

Consequently, we can firstly define $n$ time-dependent "damage risk" functions $p_{j}(\tau)$, in the intervals during which at least one of the monitored physical parameters falls outside the limits (exceedance intervals) as follows:

$p_{j}(\tau)$, with $j=1 \ldots n$

where $n$ represents the number of "damage risk" functions for the considered instant of time. Thereby, for each $i$-th exceedance interval, whose initial and final instants are indicated as $\tau_{B j, i}$ and $\tau_{E j, i}$ respectively, it is possible to define a time-independent "interval-related damage risk" function using the following formulation:

$f_{\mathrm{j}, \mathrm{i}}\left(p_{\mathrm{j}}(\tau), \tau_{B j, i}, \tau_{E j, i}\right)$, with $j=1 \ldots n$ and $i=1 \ldots N s_{j}$

where $N s_{j}$ is the total number of the intervals during which the exceedances occur. 
Furthermore, it is possible to define an "overall damage risk" function (i.e. taking into account the values of all $f_{\mathrm{j}, \mathrm{i}}$ functions in all the intervals) relative to the $j$-th "damage risk" function, given by:

$g_{\mathrm{j}}\left(f_{j, 1}, f_{j, 2}, \ldots, f_{j, N s j}\right)$, with $j=1 \ldots n$

Finally, it will be possible to obtain a "comprehensive operative damage risk indicator" $(O P)$ by means of a function that combines all the "overall damage risk" functions $g_{\mathrm{j}}$ :

$O P=F\left(g_{1}, g_{2}, \ldots, g_{n}\right)$

Generally speaking, the damage to which a given work of art is subjected is caused by different factors that could be characterized by synergic relationships. For sake of simplicity, we limited our attention to the typical physical parameters that are usually monitored in museums, namely air temperature $(T)$ and air relative humidity $(R H)$. In this case, we could then assume that the total risk of damage is caused by the times that the above-cited parameters fall outside the safety limits established by technical standards and regulations.

On the other hand, it must not be overlooked the fact that the curator is confronted with materials that can be organic or inorganic, and that when organic materials are involved, other than the causes of the risk of damage, the possible degradation and/or stress effects could also be used to assess such risk.

Therefore, from the perspective of someone who is intended to develop an operative damage risk indicator the approach can be represented by the action diagram shown in Figure 3.

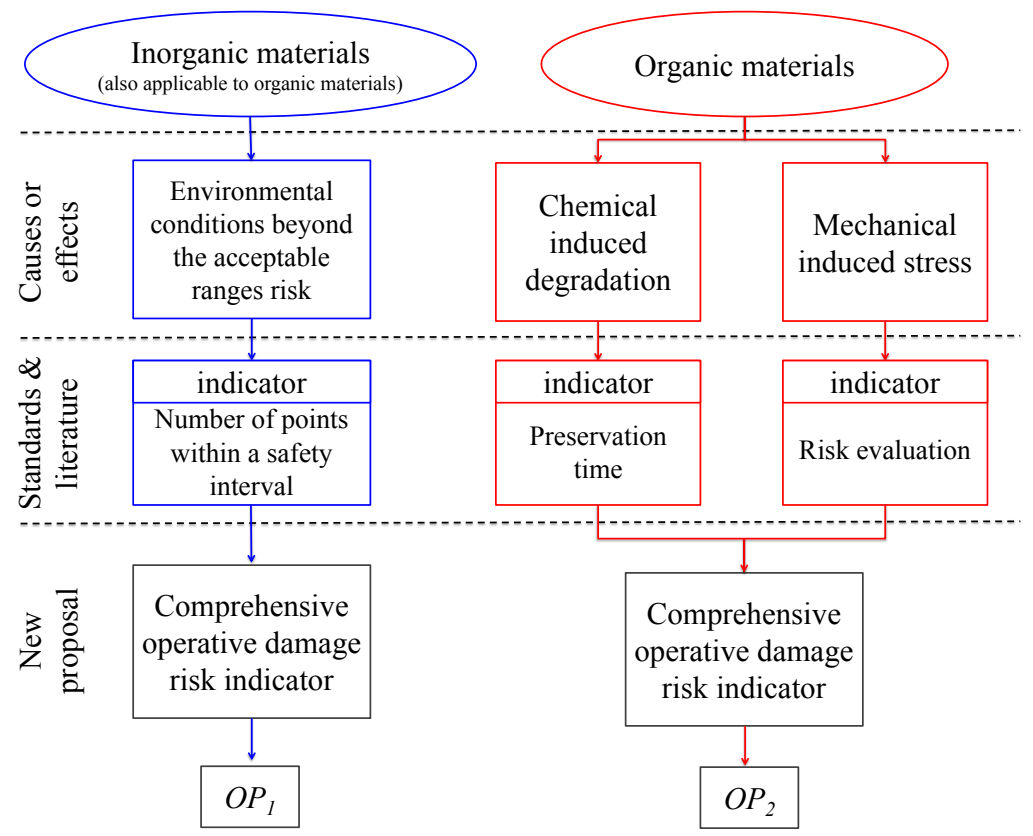

Figure 3. Logical scheme showing the proposed intervention approach.

Figure 3 shows, indeed, that the risk of damage could be estimated in three main ways, depending on the typology of the considered material. In particular, for both inorganic and organic materials the extent of the probable risk could be directly linked to monitored data of $T$ 
and $R H$ parameters (i.e. risk causes), by means of indicators related to recommended safety intervals. As for inorganic materials, other methods for the assessment of the probable risk of damage could be utilized; specifically, depending on the kind of damage analysed (i.e. risk effect), two types of indicators can be found in literature. The possible comprehensive operative damage risk indicator should therefore combine the above-cited different aspects, in order of suitably being used by curators in the contracts drafting with companies providing technical HVAC services for museums. Equation (4) shows, in fact, that the "overall damage risk" is given by a proper contribution of indoor parameters (i.e. $T$ and $R H$ ) and damage effects induced to the work of art (i.e. chemical degradation and/or mechanical stress).

Such comprehensive and operational indicators $O P$ might reasonably depend on indexes already used for assessing the appropriate indoor microclimatic conditions of museums.

\subsection{Tools used for building-up the damage risk indicators}

In the following sub-sections the above-cited indexes [25] will be described, attempting to estimate the probable damage risk in connection with assigned environmental conditions related to pre-set reference values, in order to select some of them for singling out the new proposed OP indicators.

\subsubsection{Performance Index (PI)}

The Performance Index (PI) is defined [26, 27] as the percentage of time during which a measured parameter lies within its recommended safety range. Specifically, $P I$ is computed as the percentage of hours, for each month of a given year, in which the values of the considered measured parameters fall inside the ranges recommended by [18] and [28]. In particular, in the present work, only the $T$ and $R H$ physical parameters have been considered.

$P I$ 's most important feature is represented by the definition of microclimate "warning limits" (such as, indeed, $T$ and $R H$ ) not to be exceeded, which should be set up also in accord with the curator knowledge and experience. For this reason, $P I$ is often used to verify whether a museum's HVAC system was suitably designed in order to maintain the microclimatic conditions required for the preservation of the exhibited works of art, as suggest by the Italian Standard UNI 10829 [18] and the Italian Ministerial Decree [28, 29].

\subsubsection{Preservation Index (IPI)}

The Image Permanence Institute proposes a "Preservation Index" (IPI) [30], based on a detailed study of the hydrolysis cellulose acetate reaction, to be used as gauge of the combined effects that the indoor $T$ and $R H$ have on the exhibited works of art composed by organic materials.

The mathematical expression of the IPI (expressed in lifetime years), related to the kinetics reaction, is reported in equation (5).

$I P I=\frac{e^{\frac{95220-134.9 \times R H}{8.314 \times T}+0.0284 \times R H-28.023}}{365}$

where $T\left({ }^{\circ} \mathrm{C}\right)$ and $R H(\%)$ are, respectively, given assigned values of $T$ and $R H$, supposed to remain constant and characterizing the considered environment. 


\subsubsection{Equilibrium Moisture Content (EMC)}

The Equilibrium Moisture Content (EMC), expressed in percentage (\%), can be defined as the moisture content reached at the equilibrium with the indoor environmental $T$ and $R H$ values [31]. The $E M C$ has been used by the Image Permanence Institute in order to obtain information regarding the possible influence of such parameters ( $T$ and $R H$ ) on the risk of damage for the works of art.

Indeed, according to the $E M C$ calculation method proposed by the IPI [32], environmental conditions are rated as "Good" or "Risk", based on the EMC values obtained from the monitored data of the $T$ and $R H$ parameters. In fact, the amount of moisture in the environment and the degree of fluctuation between periods of humidity and of dryness, are the factors, which promote mechanical (and/or physical) damage in vulnerable materials such as works of art (Table 1).

Table 1. "Mechanical damage" evaluation scales proposed by the Image Permanence Institute.

\begin{tabular}{ccc}
\hline \multicolumn{3}{c}{ Mechanical damage } \\
\hline Min \% EMC & Max \% EMC & RATE \\
\hline \hline$>5$ & $<12.5$ & Good \\
$<5$ & $>12.5$ & Risk \\
\hline
\end{tabular}

The expression for the calculation of the EMC parameter proposed by the Image Permanence Institute [33] is given by equation (6).

$E M C=\frac{1800}{W} *\left(\frac{K \times H}{1-K \times H}+\frac{K_{1} \times K \times H+2 \times K_{1} \times K_{2} \times K^{2} \times H^{2}}{1+K_{1} \times K \times H+K_{1} \times K_{2} \times K^{2} \times H^{2}}\right)$

where $T$ represent the air temperature $\left({ }^{\circ} \mathrm{C}\right), H=R H / 100$, with $R H$ in (\%) air relative humidity, and $W, K, K_{1}, K_{2}$ are the adsorption coefficients, that is:

$$
\begin{aligned}
& W=349+1.29 \times T+0.0135 \times T^{2} \\
& K=0.805+0.000736 \times T-0.00000273 \times T^{2} \\
& K_{1}=6.27-0.00938 \times T-0.000303 \times T^{2} \\
& K_{2}=1.91-0.0407 \times T-0.000293 \times T^{2}
\end{aligned}
$$

\section{DEFINITION OF TWO COMPREHENSIVE OPERATIVE DAMAGE RISK INDICATORS: $O P_{1}$ AND $O P_{2}$}

The literature indexes reported in section 3 are mainly used to assess whether the safety limits suggested for the environmental physical parameters of interest (in the present case, $T$ and $R H$ ) are respected or not. They have not been specifically designed for taking into consideration the economic issues related to a possible damage risk condition, contrarily to what curators are 
often called to assess. Therefore, these literature indexes do not appear to be suitable enough tools to help curators in negotiating the stipulation of contracts with the "Global Service".

Hence, on the basis of the above-mentioned considerations, and in reference to what previously outlined by the logical scheme of Figure 3, in the following the cases of inorganic and organic materials will be treated separately, in sight of singling out comprehensive operative damage risk indicators $\left(O P_{i}\right)$ to be used by curators in their contract's assessment:

$$
O P_{i}=(\text { function }(P I) \mid \text { function }(I P I, E M C))
$$

Specifically, the equation (4) will be explained in detail by considering, in the first case an indicator based on safety ranges suitable for inorganic materials (but also applicable to organic materials), and in the second case an indicator based on the degradation effects due to the environmental conditions.

\subsection{An indicator designed for inorganic and organic materials: $O P_{1}$}

As for both inorganic and organic materials, an effective indicator $\left(O P_{1}\right)$ can be usefully derived on the base of the safety ranges existing in literature and reported in the UNI 10829 Standard [18]. This approach considers not only the percentage of time during which the measured physical parameters of the indoor environment fall outside the optimal range, but also the gap between these values and the limits of the considered range over that time. Such an approach thus allows the identification of the situations in which the artefacts are more exposed to risks when the HVAC system cannot be able to ensure the required microclimatic conditions.

Starting from the limits of the indoor physical parameters suggested by the UNI 10829 Standard [18], we propose here the building up of integrated parameters based on the evaluation of doses of $T$ and/or $R H$ released by the environment surrounding the artefact under study.

Following the logical process introduced in Section 3.1, with reference to equation (1) we initially define four damage risk functions $(n=4)$ characterized by four intervals of time. Specifically, $N s_{1}$ is the number of intervals during which monitored indoor $T$ fall below the lower limit; $N s_{2}$ is the number of intervals during which monitored indoor $T$ fall above the upper limit; $N_{3}$ is the number of intervals during which monitored indoor $R H$ fall below the lower limit; $N_{4}$ is the number of intervals during which monitored indoor $R H$ fall above the upper limit.

The first function takes into account only the intervals during which $T$ values fall below the lower safety limit:

$p_{1}(\tau)=\frac{\left|T(\tau)-T_{\text {lim,lower }}\right|}{\left|T_{\text {lim,upper }}-T_{\text {lim,lower }}\right|} \quad$ when $T(\tau)<T_{\text {lim,lower }}$

The second function, instead, takes into account only the intervals during which $T$ shows values higher than the upper safety limit:

$p_{2}(\tau)=\frac{\left|T(\tau)-T_{\text {lim,upper }}\right|}{\left|T_{\text {lim,upper }}-T_{\text {lim,lower }}\right|} \quad$ when $T(\tau)>T_{\text {lim,upper }}$ 
Similarly, it is possible to define two corresponding functions for the air $R H$ :

$p_{3}(\tau)=\frac{\left|R H(\tau)-R H_{\text {lim,lower }}\right|}{\left|R H_{\text {lim, upper }}-R H_{\text {lim,lower }}\right|} \quad$ when $R H(\tau)<R H_{\text {lim,lower }}$

$p_{4}(\tau)=\frac{\left|R H(\tau)-R H_{\text {lim,upper }}\right|}{\left|R H_{\text {lim,upper }}-R H_{\text {lim,lower }}\right|} \quad$ when $R H(\tau)>R H_{\text {lim,upper }}$

Successively, with reference to equation (2), it is possible to define the "interval-related damage-risk" functions, that is:

$f_{j, i}=\int_{\tau_{B j, i}}^{\tau_{E j, i}} p_{j}(\tau) \cdot d \tau$ with $i=1 \ldots N s_{j}$ and $j=1 \ldots 4$

Hence, referring to equation (3), the overall damage risk function can be put in the form:

$g_{j}=\sum_{i=1}^{N s_{j}} f_{j, i} \quad$ with $j=1 \ldots 4$

Finally, the comprehensive operative damage risk indicator $O P_{l}$ can be defined as:

$O P_{1}=\sum_{j=1}^{4} \alpha_{j} \cdot g_{j}$

where $\alpha_{j}$ are suitable weights, described in the following.

Hence, a total of four $g$ functions are required to define the quality of the environment conditions (in terms of $T$ and $R H$ ) related to HVAC system running interruption, which may be due to maintenance or unforeseen failure.

Based on their definitions, the $g$ functions are used here to assess the operational indicator $O P_{1}$ depending on non-working periods of HVAC system, to be adopted by curators.

The $\alpha_{j}$ coefficients, reported in equation (18), are suitable weights relative to the $T$ and $R H$ parameters, representing the impact that the variations of these microclimatic parameters from the suggested ranges (i.e. $\Delta T$ and $\Delta R H$ ) have on the works of art. In particular, it was here decided to distinguish such coefficients, based on their dependence on the specific parameter, as follows: $\alpha_{1}=\alpha_{2}=f(\Delta T)$ and $\alpha_{3}=\alpha_{4}=f(\Delta R H)$. These weighting coefficients could assume different values depending not only on the required microclimatic ranges for the work of art preservation, but also on the materials that compose a given artefact, and on its exhibition "history" in the considered halls. Hence, they must be established specifically for each one of them. In the present case it was proposed to use a scale of values (Figure 4) comprised between 0.2 (minimum impact) and 1 (maximum impact), based on the consideration that the narrower the safety interval, the more sensitive the artefact is to the considered microclimate parameter [34]. These values represent, at this stage, only a tentative proposal. Of course, their definition is up to curator, depending on his experience on the relationship between the work of art wellbeing and the indoor conditions of the exhibiting rooms. 


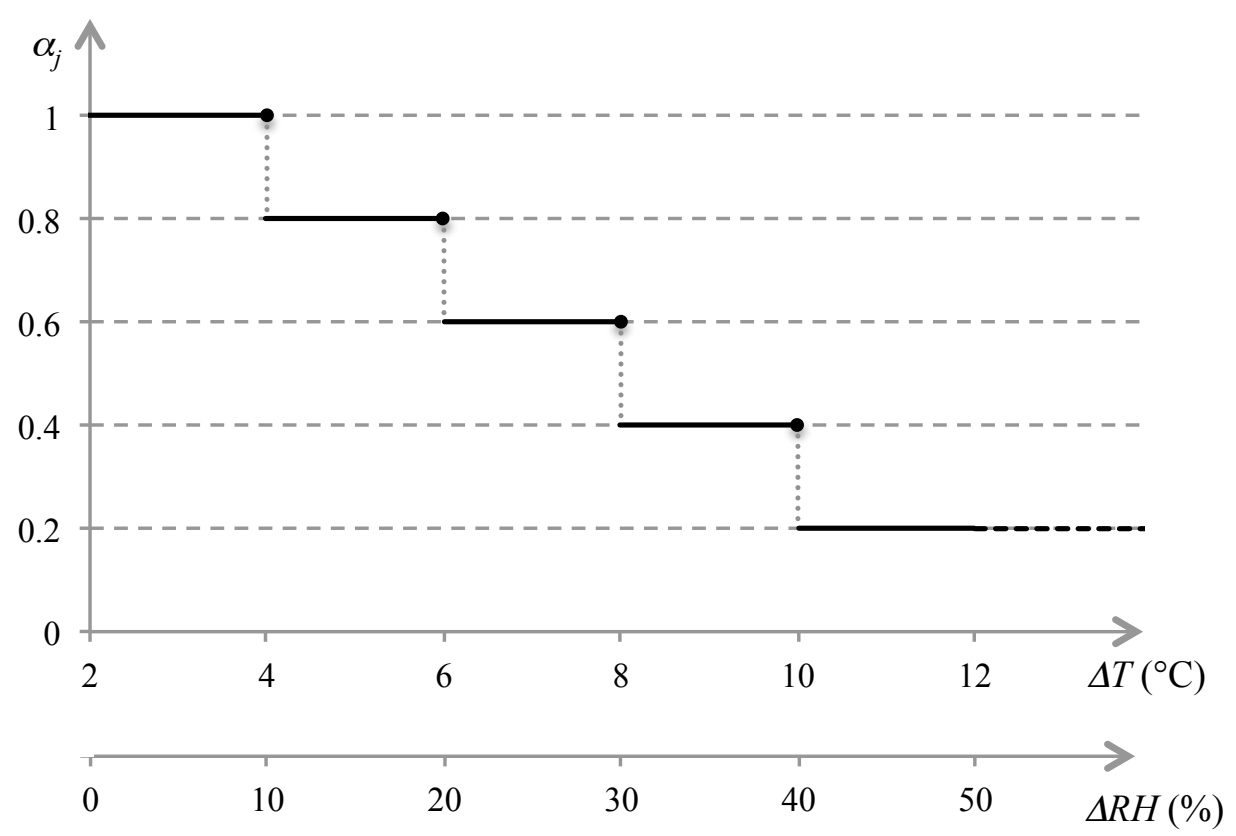

Figure 4. Proposed scale of values for the weighting coefficients based on the UNI10829 [34].

The structure of equations (16) and (17), except for the definition of the weighting parameters, is characterized by an important simplification, consisting in the implicit linearity assumption (i.e. a summation or integration) of the separate effects induced by $T$ and $R H$ (i.e. hypothesis of superposition of effects principle).

\subsection{An indicator designed for only organic materials: $O P_{2}$}

In the case of organic materials, it is proposed to implement the operational indicator $\mathrm{OP}_{2}$ by assembling the EMC and IPI risk indexes thresholds proposed by the Image Permanence Institute $[30,32]$. In particular, in order to take into account the degree of sensitivity of each of these two indexes with respect to the $T$ and $R H$ parameters it was chosen to build up the $\mathrm{OP}_{2}$ indicator as follows.

Firstly, with reference to equation (1), we define only one $(n=1)$ "damage risk" function, which, referring to the instantaneous values of $T$ and $R H$, considers when at least one of the two parameters fall outside of the safety range. That is:

$p_{1}(\tau)=\max [F(E M C(\tau)), G(I P I(\tau))]$

where $F$ and $G$ are assumed to be two proper logistic functions.

Subsequently, with reference to equation (2), the "interval damage risk" function can be defined in this case as:

$f_{1, i}=\int_{\tau_{B 1, i}}^{\tau_{E 1, i}} p_{1}(\tau) \cdot d \tau$ with $i=1 \ldots N s_{1}$

Referring to equation (3), the "overall damage risk" function (being only one damage risk in this context) can be put as follows: 
$g_{1}=\sum_{i=1}^{N s_{1}} f_{1, i}$

Finally, for this particular case, the "comprehensive operative damage risk indicator" $\left(\mathrm{OP}_{2}\right)$ coincides with $g_{l}$, therefore:

$O P_{2}=g_{1}$

The functions $F(E M C)$ and $G(I P I)$ reported in equation (19) represent a combination of logistic functions and a logistic function respectively, relative to the EMC and IPI indexes, as reported in Figure 5.
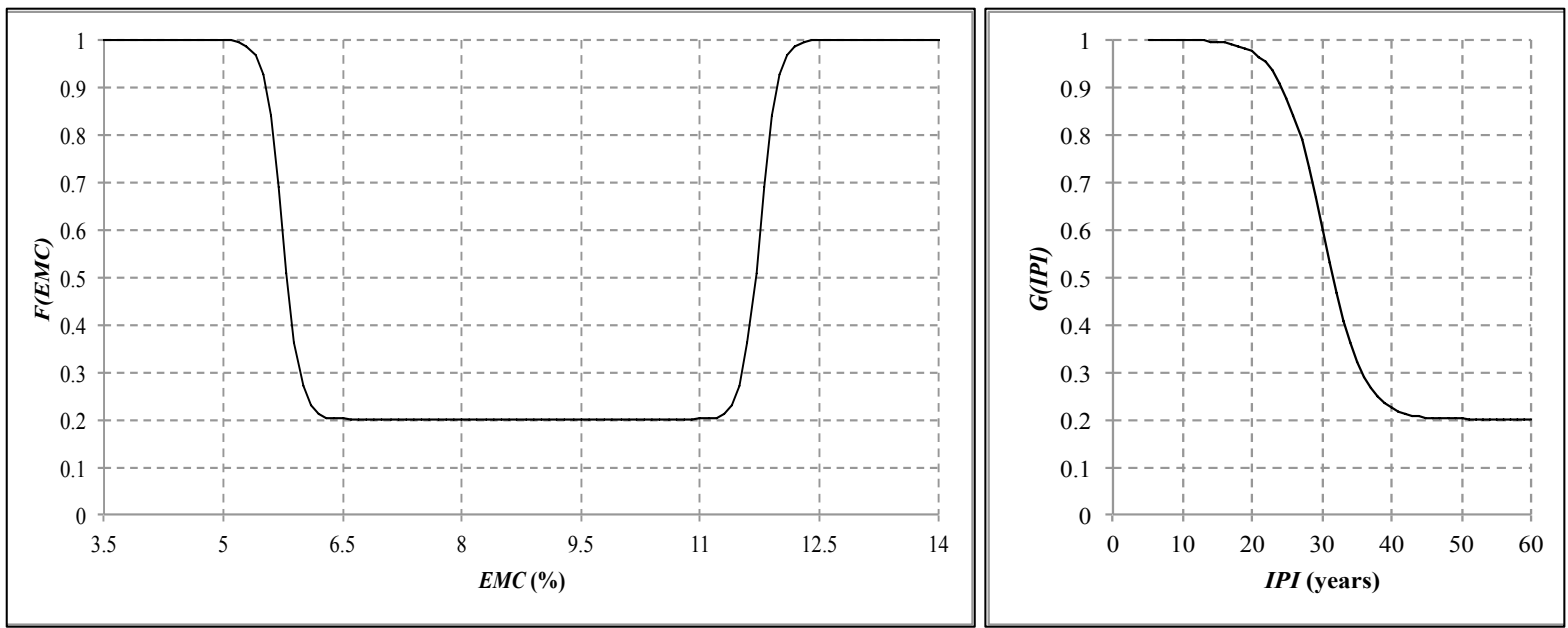

Figure 5. $F(E M C)$ and $G(I P I)$ behaviors.

It must be here underlined that, at this stage, some assumptions have been made on the $F(E M C)$ and $G(I P I)$ logistic functions, in particular it has been assumed that they return only values comprised between 0.2 (corresponding to a low risk level) and 1.0 (corresponding to a highrisk level). Also, regarding the risk evaluation scale relative to the $F(E M C)$, it was decided to assign a condition of "Risk" to values of the $E M C$ index lower than 5 and higher than 12.5 (as suggested by the Image Permanence Institute [30, 32]), and a condition of "Alert" for the cases $5<E M C$ index $<6.5$ and $11.0<E M C$ index $<12.5$; where these chosen limits of 6.5 and 11.0 approximately correspond to $R H$ values of $35 \%$ and $60 \%$ respectively, considering a range of temperatures comprised between 5 and $35^{\circ} \mathrm{C}$.

As for the risk evaluation scale relative to the $G(I P I)$, instead, the "Risk" condition has been associated to values of the IPI index lower than 10 , while the "Alert" condition to $10<I P I$ index $<50$. In this case the chosen limit values of 10 and 50 are based on authors' considerations on a table (Table I) reported in [30], namely supposing to consider a reference value of $50 \%$ for the $R H$ and to assign the "Risk" and the "Alert" conditions to values of $T$ of approximately $30^{\circ} \mathrm{C}$ and $20^{\circ} \mathrm{C}$ respectively. 


\section{APPLICATION OF THE TWO PROPOSED OP INDICATORS TO A CASE STUDY}

The feasibility of the proposed methodology has been checked in the "Museo Regionale" of Palermo (Italy), located at Palazzo Abatellis (Figure 6), two halls of which - previously subjected to a monitoring campaign of the indoor physical parameters - have been considered for an example application of the $O P_{1}$ and $O P_{2}$ indicators, above defined.

Specifically, the works of art considered in the case study, shown in Figure 7, are the following:

- the Virgin Annunciate (dated 1476), placed in exhibition hall 10, a famous painting on wood by the Italian Renaissance artist Antonello da Messina.

- the Triumph of Death (dated 1446), placed in exhibition hall 2, one of the most representative frescoes of the late Gothic painting in Italy.
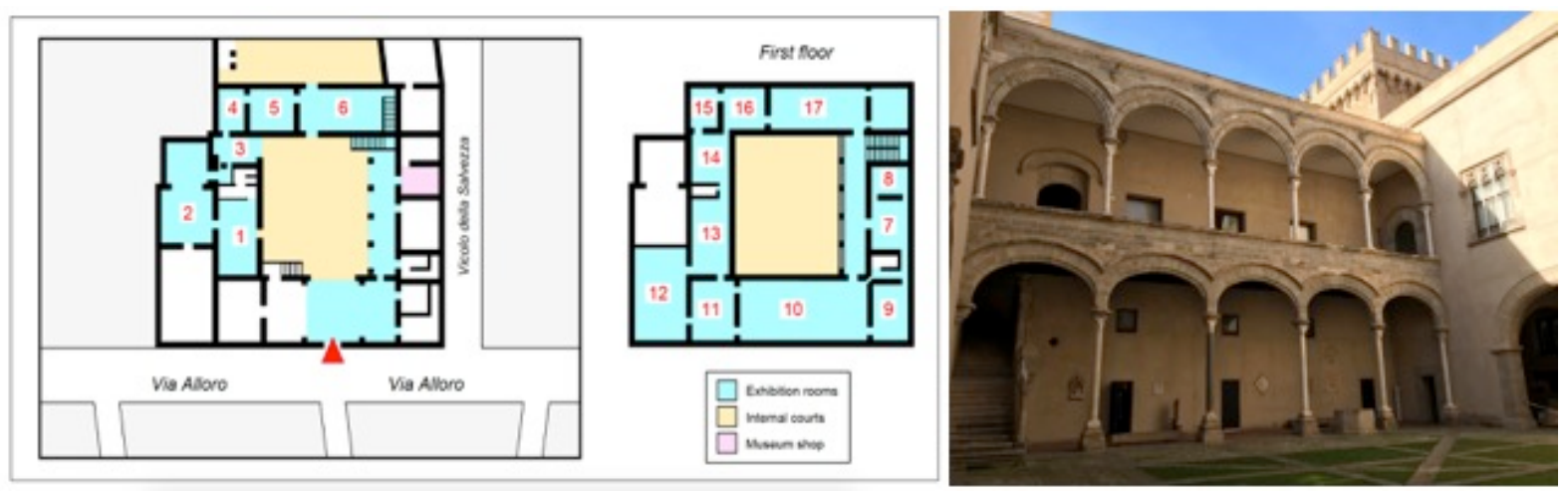

Figure 6. Palazzo Abatellis's exhibition halls' layout (left) and internal atrium view (right).
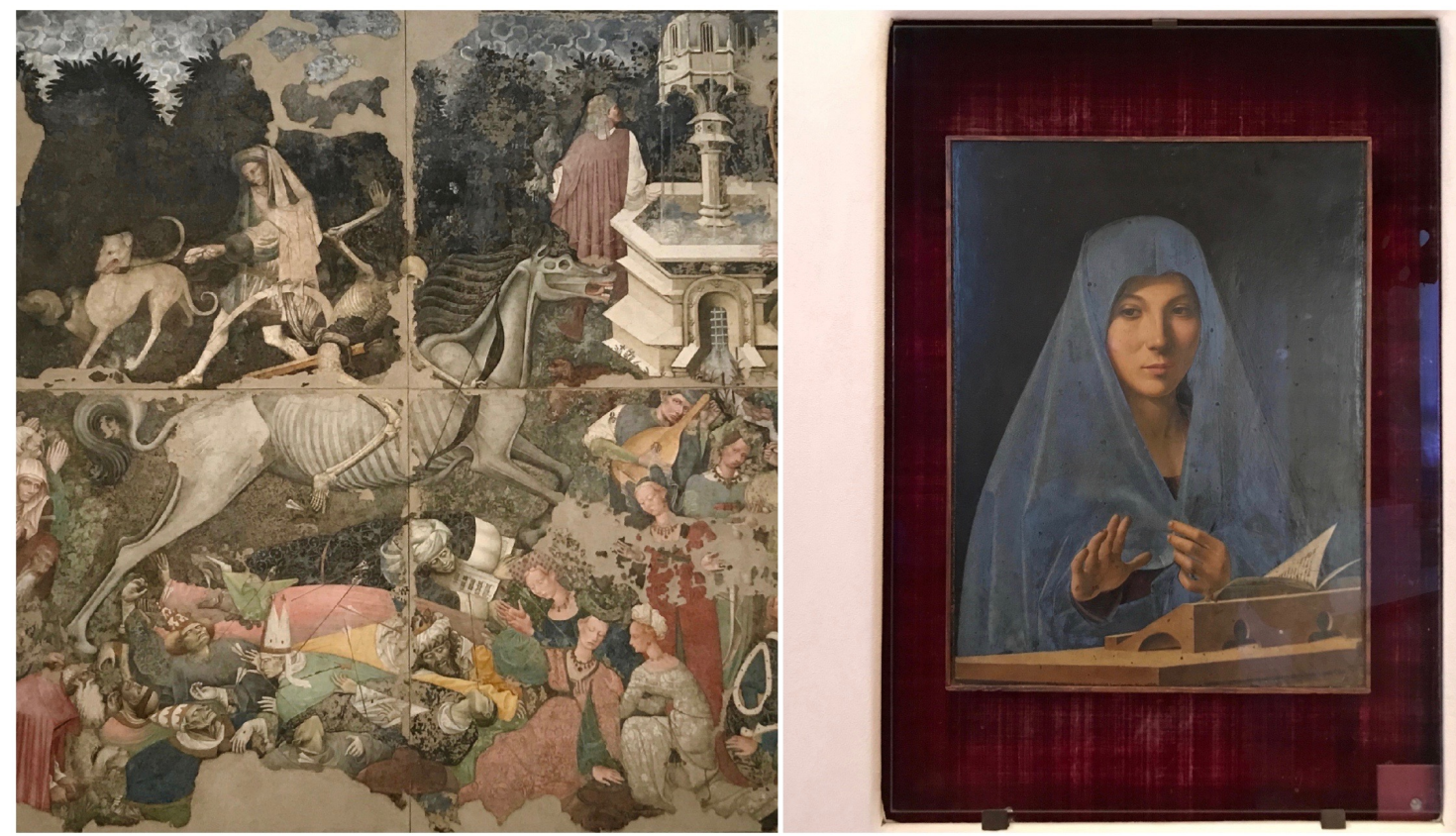

Figure 7. Triumph of Death on the left, Virgin Annunciate on the right. 
As for the recommended ranges of $T$ and $R H$ for these kinds of works of art, those suggested by the Italian standard UNI 10829 [18] and the Italian Ministerial Decree of 10 May 2001 [28] are the following:

- for the Virgin Annunciate (painting on wood): $T$ comprised between $19^{\circ} \mathrm{C}$ and $24^{\circ} \mathrm{C}$ and $R H$ comprised between $50 \%$ and $60 \%$;

- for the Triumph of Death (fresco): $T$ ranging from $10^{\circ} \mathrm{C}$ to $24^{\circ} \mathrm{C}$ and a $R H$ varying between $55 \%$ and $65 \%$.

The proposed approach preliminarily requires an analysis of the environmental conditions of the considered exhibition hall without the presence of the HVAC. This circumstance, corresponding to a HVAC system failure, in fact, represents free-floating conditions. In such situation the indoor parameters of $T$ and $R H$ may be obtained by a dynamic simulation or by a monitoring campaign. The latter, in this case, has been performed in the exhibition halls 2 (site of the Triumph of Death) and 10 (hosting the Virgin Annunciate) for a whole year.

For the sake of completeness, in order to show the seasonal variations of the climate characterizing the studied zone, in which the museum is located, the monthly trend of the mean values of external $T$ and $R H$ have been reported in Figure 8.

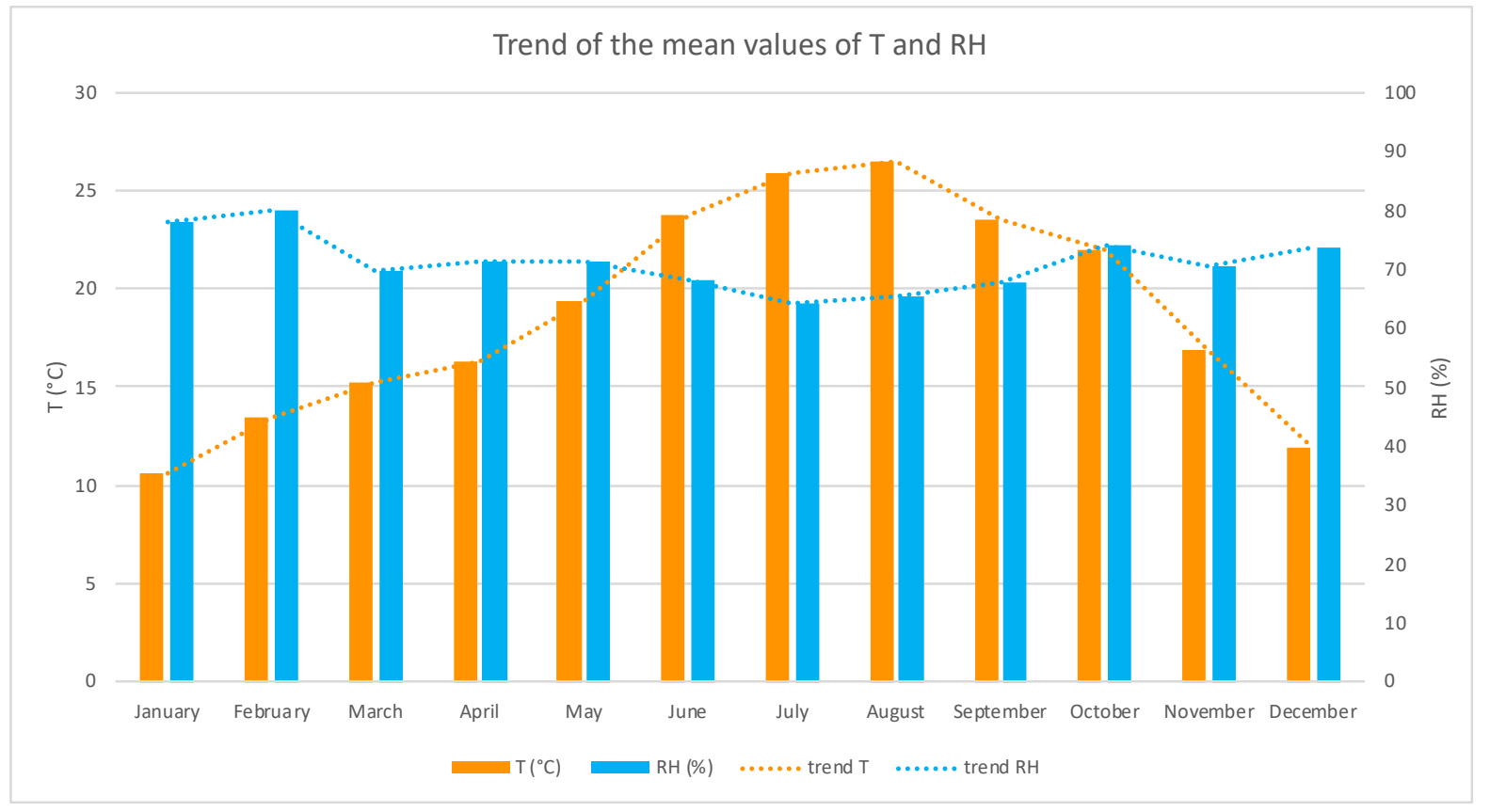

Figure 8. Monthly trend of the mean values of external $T$ and $R H$ monitored.

Further, for the assessment of the new $O P_{1}$ and $O P_{2}$ indicators, it has been hypothesized to install an ideal air conditioning system inside Palazzo Abatellis, able to maintain constant values of $T$ and $R H$ indoor parameters. In particular, for the indoor $T$ a value equal to $21^{\circ} \mathrm{C}$ has been set for both the exhibition rooms hosting the two works of art; while the values of the $R H$ in the two rooms have been set equal to the average of the limit values suggested by the legislation for the relative type of artwork exhibited, that is 55\% for the Virgin Annunciate and $60 \%$ for the Triumph of Death. 


\section{RESULTS}

The simulations were carried out hypothesizing three different periods of interruption of the HVAC system for maintenance: 5, 15 and 30 consecutive days. A total number of 8760 simulations for each of the three scenarios were carried out, starting from the first hour of the first day of the year and postponing the service interruption of one hour each time. The corresponding simulation model has been implemented by means of the MATLAB ${ }^{\mathrm{TM}}$ environment.

In order to show the potential of each of the two new introduced indicators to be sensible to both $T$ and $R H$ parameters simultaneously, as a first step it was decided here to report a comparison among the complementary values of the index $P I(T-R H)$, and the indicators $O P_{1}$ and $O P_{2}$ relative to the 30 days interruption period. This choice relies on the fact that for such interruption period the differences between the results relative to the different indicators become more evident.

The results of the simulations were summarized by means of a monthly statistical graphical analysis, reported in Figure 9, using a boxplot visual representation for the obtained results.

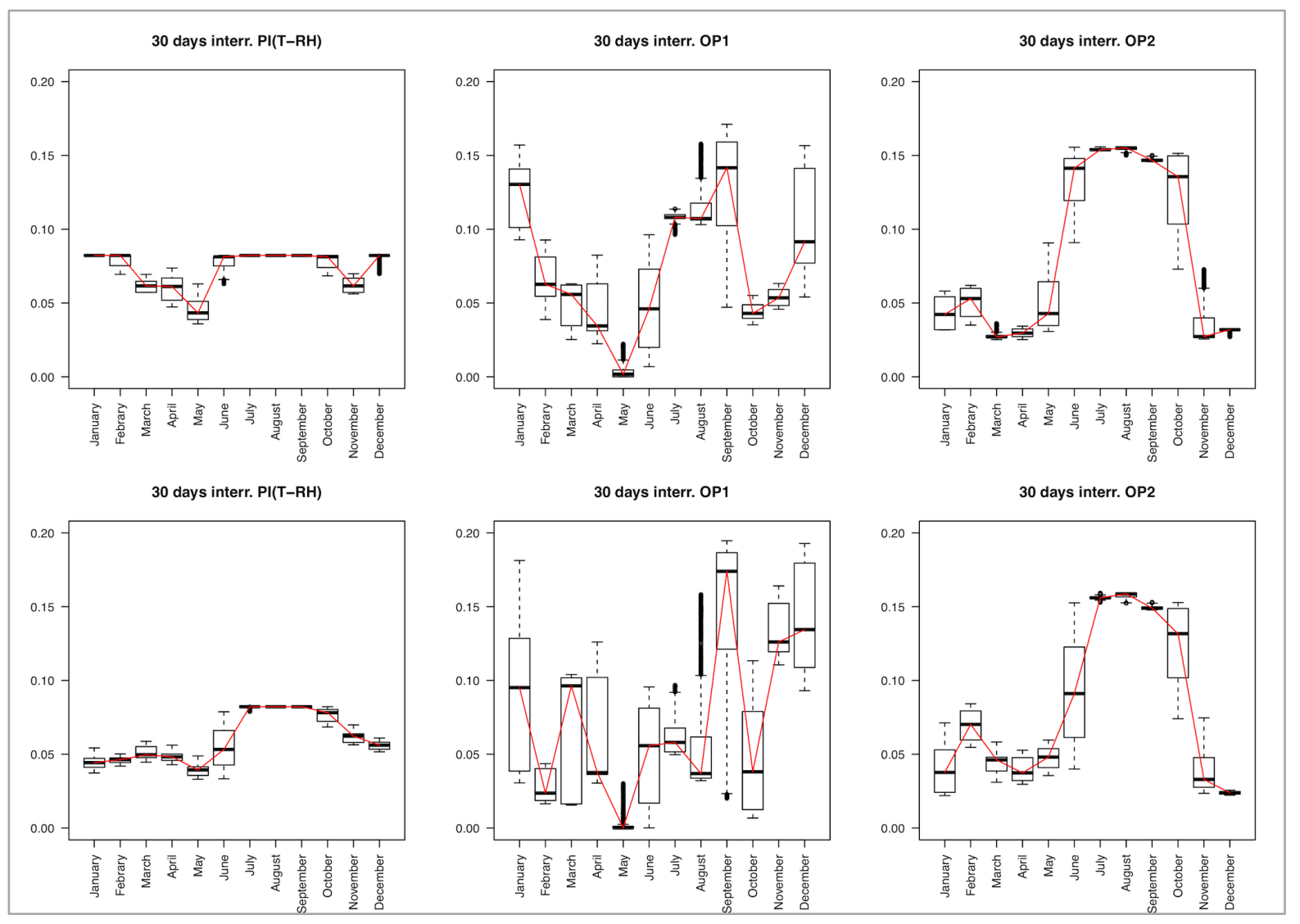

Figure 9. Comparison of the $P I(T-R H), O P_{1}$ and $O P_{2}$ indicators, relative to the Virgin Annunciate "top" and the Triumph of Death "bottom" for the 30 days interruption period.

To allow the comparison among the index $P I$ and the two $O P$ indicators, it was decided to normalize the results obtained for each indicator using a scale of values comprised between 0 and 1. In this scale, " 1 " represents the highest level of damage risk (critical conditions) for the work of art, while " 0 " corresponds to the lowest level of damage risk (acceptable conditions). 
Specifically, the maximum and minimum values used to normalize the results are those relative to the case in which the HVAC system is not working for a whole year (i.e. free-floating conditions in the environment for the entire period), since the main purpose here is to compare the indicators among them, and not comparing their absolute values.

By observing Figure 8 it can be noted how the $P I(T-R H)$ index shows a quite flat trend presenting only a very slight variations during summertime. Therefore, this index does not give very useful information.

As for the $O P_{1}$ indicator, this is the one that presents a wider variation as regards both the symmetry of the distribution and the dispersion of the values for both works of art.

The $O P_{2}$ indicator presents monthly trends similar to those of the $O P_{1}$ for both artefacts, although the dispersion of the values looks less accentuated, showing a possible critical period during the summer season.

We want here to underline that for the $O P_{1}$ simulations we considered an environmental physical parameters' data set rebuilt from the actual data monitored in free-floating conditions by means of a "response time constant" of approximately three days for the examined works of art [35]. Specifically, such "response time constant" is characteristic of the single works of art, and takes into consideration how the artefact reacts to the modality of variation of the physical parameters; that is, it considers the time necessary to have an appreciable relative variation of the artefacts' chemical and mechanical characteristics, in terms of degradation.

The results obtained for $P I(T-R H), O P_{1}$ and $O P_{2}$, relative to the present case study, are reported in Figure 10, where $P I(T-R H)$ appears to have a flattened trend with respect to $O P_{1}$ and $O P_{2}$, meaning that it does not seem to be very influenced by the seasonal variations.

The differences between $P I(T-R H), O P_{1}$ and $O P_{2}$ observed in Figure 10 are ascribable to the intrinsic definition of the considered indicators. In fact, $P I(T-R H)$ index does not consider the distance of the actual values from the suggested safety limits of the parameters $T$ and $R H$.

On the contrary, the $O P_{l}$ indicator has been specifically built-up to evaluate the actual distance of the monitored values of the parameters $T$ and $R H$ from the relative safety ranges limits and it also considers the "response time constant" of the specific work of art. However, the fact that the choice of the weighting coefficients to be attributed to each work of art are up to the curators decision represents a critical aspect, being such parameters crucial points in the definition of the indicator. The $\mathrm{OP}_{2}$, finally, has been designed to have a strong dependence on the combined effects of both $T$ and $R H$.

Graphs such those reported in the following Figure 10 allow curators to immediately identify the involved risks for each type of work of art, and for each period of interruption. 


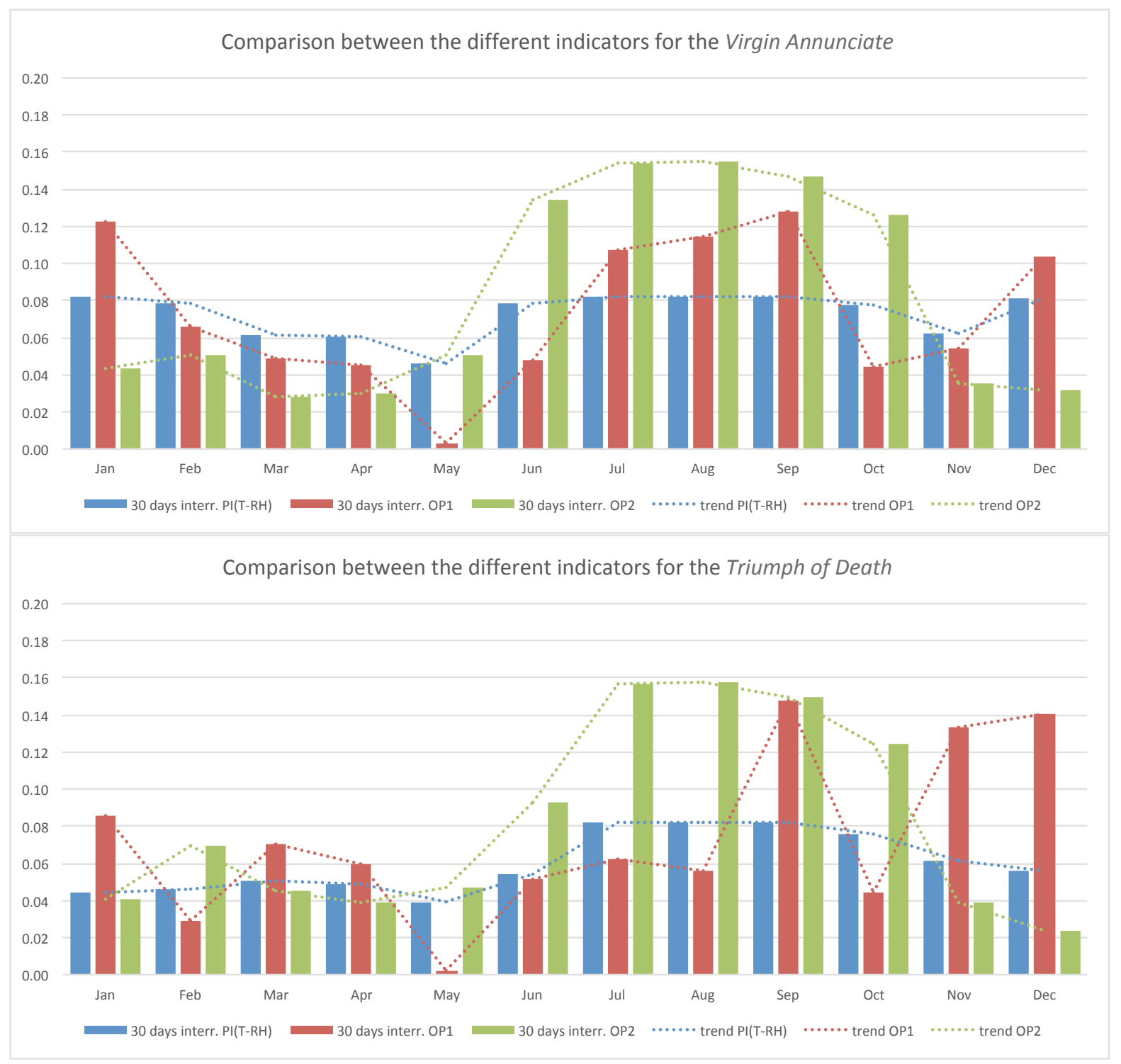

Figure 10. Comparison of the $P I(T-R H), O P_{1}$ and $O P_{2}$ indicators relative to the Virgin Annunciate "top" and to the Triumph of Death "bottom" for an interruption period of 30 days.

\section{DISCUSSIONS}

The following two sub-sections respectively discuss the possibility of embedding economyrelated considerations into the structure of the $O P_{i}$ indicators, and the applicability of these indicators to other climate situations different from those of the analyzed site.

\subsection{Embedding in the $O P$ indicators economic-related factors}

As previously mentioned, the proposed $O P_{1}$ and $O P_{2}$ indicators are meant to be adopted as decision-making tools to support curators in regulating the contracts with the companies responsible for the management of the HVAC systems (i.e. establishing the maximum time of acceptable disservice and evaluating the planned maintenance interruptions). For this purpose, in order to motivate the companies to solve possible HVAC failures in the shortest conceivable time, an Economic Penalty (EP) function could be included in the contracts, to be scaled according to the time of interruption of the system. 
Assigning an economic penalty $E P$ is not an easy task, since the economic value of a work of art is of difficult estimation (sometimes priceless); we suppose here to commensurate the economic penalty with the probability of occurrence of the HVAC failure and the consequent supposed amount of damage estimated for the work of art. In fact, the contractors should "pay the bill when they fail to respond to an emergency within the agreed-on time period" [23]. The tentative proposed relationship for the calculation of EP could assume the form indicated in equation (23):

$$
E P=f(O P, P)
$$

In equation (23) $O P$ tries to take into account the technological/engineering aspect of the problem by integrating the physical indoor parameters, the probability of failure occurrence of the HVAC system, and a time-related parameter. $P$ should consider the economic aspect, representing an estimate of the amount of damage related to the work of art (or to the whole museum), for which determination the curator's (stakeholders) support/expertise is fundamental.

As an example, Table 2 contains the values of $E P$ for the works of art considered in the case study presented here, and calculated as a product of $O P_{2}$ and $P$ (that is, $E P=O P_{2} \times P$ ), assuming to assign to $P$ a tentative value of $1000 € /$ day. This totally fictitious value is simply aimed at making a comparison among the different relevancies that the occurrence of the hypothesized interruption period in the different months of the year could have on the contracts.

Table 2. Tentative EP evaluation for the considered case study, applied to the Virgin Annunciate.

\begin{tabular}{|c|c|c|c|c|c|c|c|c|c|c|c|c|c|}
\hline \multicolumn{14}{|c|}{ Values of $\boldsymbol{E P}=\boldsymbol{f}\left(\boldsymbol{O P}_{2}, \boldsymbol{P}\right)$ - expressed in $\boldsymbol{€} / \mathbf{d a y}-$ applied to the Virgin Annunciate } \\
\hline & $\begin{array}{l}\text { in which the } \\
\text { ption occurs }\end{array}$ & Jan & Feb & Mar & Apr & May & June & July & Aug & Sept & Oct & Nov & Dec \\
\hline \multirow{3}{*}{ 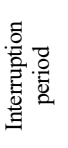 } & $1-5$ days & 7.28 & 8.53 & 4.46 & 4.71 & 7.52 & 23.51 & 25.64 & 25.95 & 24.31 & 22.32 & 4.37 & 5.36 \\
\hline & $6-15$ days & 21.58 & 25.66 & 13.57 & 14.51 & 23.41 & 69.25 & 76.92 & 77.78 & 73.12 & 65.83 & 14.18 & 16.05 \\
\hline & $16-30$ days & 43.56 & 50.27 & 28.08 & 29.69 & 50.13 & 134.03 & 154.20 & 154.59 & 147.02 & 125.73 & 34.94 & 31.52 \\
\hline
\end{tabular}

\subsection{About the extensibility of the obtained results to different climatic conditions}

It must be specified that the results obtained in the presented case study are based on the monitoring of $T$ and $R H$, in free-floating conditions, performed for a whole year in the halls housing the two works of art. This represents a peculiar case, since such indoor monitored data are not usually available. In order to consider the aspects related to climate characterizing the site where the museum is located, a possible further step is represented by the implementation, in a dynamic simulation model, of a function linking the outdoor monitored data with the indoor microclimate conditions, by considering the thermal inertia of the building. In particular, the indoor microclimatic conditions could be approximately obtained from the external climatic data assuming certain values of thermal capacity and thermal resistance for the building components. 


\section{CONCLUSION}

The present work started from considerations regarding the comparison of some currently available Standards and indexes for the implementation of two comprehensive operative damage risk indicators $\left(O P_{1}\right.$ and $O P_{2}$ here introduced) able to provide an evaluation of the microclimate related risk for works of art, in order to help museums curators in stipulating contracts with HVAC maintenance and management companies, by also considering the economic aspects. Furthermore, these indicators could also be suitable for planning the management and maintenance procedures of museums' HVAC systems.

The feasibility of the $O P_{1}$ and $O P_{2}$ has been here checked by means of an example application involving the "Museo Regionale" of Palermo (Italy).

Results showed that, contrary to what is provided by $P I(T-R H)$, indicators $O P_{1}$ and $O P_{2}$, make it possible to detect the most critical periods for the works of art, since they are able to account for both seasonal variations and the combined effects of $T$ and $R H$. As an example, by analyzing the results related to the Virgin Annunciate it is possible to note how the new indicators $O P_{1}$ and $O P_{2}$ present maximum and minimum values that differ from each other by at least one order of magnitude: $O P_{1, \max }=0.13$ in September and $O P_{1, \min }=0.003$ in May; $O P_{2, \max }=0.15$ in August and $O P_{2, \min }=0.03$ in March. While the same cannot be said with regard to $P I(T-R H)$; in fact, $P I(T-R H)_{\max }=0.08$ in September and $P I(T-R H)_{\min }=0.04$ in May.

The case study carried out via such application showed that further investigations must be conducted. In particular, adequate attention must be paid to the influence that both the climate zone in which the museum is sited and the season of the year in which the HVAC disservice occurs have on the physical parameters ( $T$ and the $R H$ ) variations. Moreover, the aspect regarding the link between the different types of works of art that can be present in a museum, and/or their simultaneous presence within the same exhibition hall, should also be further explored. As regards, instead, the economic aspects, it must be highlighted the difficulty in quantifying the damage risk related to the artefacts, due to the difficulty in assessing a proper monetary value for certain particular types of works of art, and also to the appropriate form that the relationship for the calculation of $E P$ should assume.

In conclusion, the cooperation between curators, technicians and researchers working on the assessment of the $O P$ indicators is essential for future development in this field of study.

\section{FUNDING SOURCES}

This research did not receive any specific grant from funding agencies in the public, commercial, or not-for-profit sectors.

\section{REFERENCES}

1. K. Gysels, F. Delalieux, F. Deutsch, R. Van Grieken, D. Camuffo, A. Bernardi, G. Sturaro, H. J. Busse, M. Wieser, Indoor environment and conservation in the Royal Museum of Fine Arts, Antwerp, Belgium, Journal of Cultural Heritage, Vol. 5, pp 221-230, 2004.

2. A. Bernardi, V. Todorov, J. Hiristova, Microclimatic analysis in St. Stephan's church, Nessebar, Bulgaria after interventions for the conservation of frescoes, Journal of Cultural Heritage, Vol. 1, pp 281-286, 2000. 
3. J. Ferdyn-Grygierek, A. Baranowski, Internal environment in the museum buildingAssessment and improvement of air exchange and its impact on energy demand for heating, Energy and Buildings, Vol. 92, pp 45-54, 2015.

4. G. Salvadori, F. Fantozzi, M. Rocca, F. Leccese, The energy audit activity focused on the lighting systems in historical buildings, Energies, Vol.9 (12), pp. 1-13, 2016.

5. D. Milone, G. Peri, S. Pitruzzella, G. Rizzo, Are the Best Available Technologies the only viable for energy interventions in historical buildings?, Energy and Buildings, Vol. 95, pp 3946, 2015.

6. L. Tronchin, K. Fabbri, Energy and Microclimate Simulation in a Heritage Building: Further Studies on the Malatestiana Library, Energies 2017, 10, 1621.

7. M. La Gennusa, G. Rizzo, G. Rodonò, G. Scaccianoce, People comfort and artwork saving in museums: comparing indoor requisites, Int. J. Sustainable Design, Vol. 1, No. 2, pp 199-222, 2009.

8. R. Kramer, J. Van Schijndel, H. Schellen, Dynamic setpoint control for museum indoor climate conditioning integrating collection and comfort requirements: Development and energy impact for Europe, Building and Environment, Vol. 118, pp 14-31, 2017.

9. G. Pavlogeorgatos, Environmental parameters in museums, Building and Environment, Vol. 38, pp 1457 - 1462, 2003.

10. F. Leccese, G. Salvadori, F. Feltrin, R. Morozzi, P. Nieri, Study on the suitable lighting design of Beato Angelico's artworks displayed at the National Museum of San Matteo in Pisa (Italy), IOP Conference Series: Materials Science and Engineering, Vol. 364 (1), pp.1-8, 2018.

11. M. La Gennusa, G. Rizzo, G. Scaccianoce, F. Nicoletti, Control of indoor environments in heritage buildings: experimental measurements in an old Italian museum and proposal of a methodology, Journal of Cultural Heritage, Vol. 6, pp 147-155, 2005.

12. C. Gebhardt, D. Konopka, A. Borner, M. Mader, M. Kaliske, Hygro-mechanical numerical investigations of a wooden panel painting from "Katharinenaltar" by Lucas Cranach the Elder, Journal of Cultural heritage, Vol. 29, pp 1-9, 2018.

13. E. Lucchi, Multidisciplinary risk-based analysis for supporting the decision making process on conservation, energy efficiency, and human comfort in museum buildings, Journal of Cultural Heritage, Vol. 22, pp 1079-1089, 2016.

14. H. E. Silva, F. M. A. Henriques, Preventive conservation of historic buildings in temperate climates. The importance of a risk-based analysis on the decision-making process, Energy and Buildings, Vol. 107, pp 26-36, 2015.

15. S. Sharif, V. Esmaeili, Effects of temperature and relative humidity on permanence of Buyid silk, Journal of Cultural heritage, Vol. 27, pp 72-79, 2017.

16. M. La Gennusa, G. Lascari, G. Rizzo, G. Scaccianoce, Conflicting needs of the thermal indoor environment of museums: In search of a practical compromise, Journal of Cultural Heritage, Vol. 9, No. 2, pp 125-134, 2008.

17. D. Camuffo, Microclimate for Cultural Heritage, Elsevier Science B.V., Amsterdam, The Netherlands, 1998.

18. UNI 10829:1999. Works of art of historical importance - Ambient conditions or the conservation - Measurement and analysis. 
19. UNI EN 15757:2010 - Conservazione dei Beni Culturali - Specifiche concernenti la temperatura e l'umidità relativa per limitare i danni meccanici causati dal clima ai materiali organici igroscopici. Milano: UNI - Ente Italiano di Unificazione, 2010.

20. R. Y. Kwak, A. Takakusagi, J. Y. Sohn, S. Fujii, B. Y. Park, Development of an optimal preventive maintenance model based on the reliability assessment for air-conditioning facilities in office buildings, Building and Environment Vol. 39, pp 1141-1156, 2004.

21. AICARR - Associazione Italiana Condizionamento dell'Aria Riscaldamento Refrigerante, Linee guida sulla manutenzione degli impianti di climatizzazione, Milano, Italy, 2004.

22. G. P. Sullivan, R. Pugh, A. P. Melendez, W. D. Hunt, Operations \& Maintenance Best Practices - A Guide to Achieving Operational Efficiency (Release 3), Pacific Northwest National Laboratory for the Federal Energy Management Program, U.S. Department of Energy, 2010.

23. PECI - Portland Energy Conservation Inc., Operation and Maintenance Service Contracts Guidelines for obtaining Best-Practice Contracts for Commercial Buildings, O\&M Best Practice Series, Portland, USA, 1997.

24. ASHRAE Handbook Application, Chapter 35 - Operation and maintenance management. American Society of Heating, Refrigerating and Air-Conditioning Engineers Inc., 2001.

25. A. Galatioto, S. Pitruzzella, G. Scaccianoce, D. Milone, Regional policies for sustainability in the Mediterranean countries: the role of a proper HVAC system maintenance in museums. Applied Mechanics and Materials, Vols. 316-317, pp 1147-1151, 2013.

26. S. P. Corgnati, V. Fabi, M. Filippi, A methodology for microclimatic quality evaluation in museums: application to a temporary exhibit, Building and Environment, Vol. 44, No. 6, pp 1253-1260, 2009.

27. M. Filippi, S. Corgnati, R. Ansaldi, Certification of indoor environmental quality: application of a classification method to a case study, Proceeding of CLIMAMED 2006 International Conference, Lyon, September 2006.

28. Ministerial Decree 10 may 2001, Ministry for Arts and Culture, Guidelines on technicalscientific criteria for application of standards in museums - Article 150, paragraph 6, Law by Decree n. 112/1998, Italian Republic's Official Gazette, 19 October (2001), n. 244, (in Italian).

29. S. P. Corgnati, M. Filippi, Assessment of thermo-hygrometric quality in museums: Method and in-field application to the "Duccio di Buoninsegna" exhibition at Santa Maria della Scala (Siena, Italy), Journal of Cultural Heritage, Vol. 11, pp 345-349, 2010.

30. J. M. Reilly, D. W. Nishimura, E. Zinn, New Tools for Preservation, assessing long-term environmental effects on library and archives collections, The Commission on Preservation and Access, Washington D.C. (1995).

31. Dario Camuffo, Microclimate for Cultural Heritage, Elsevier, 2013.

32. Understanding Preservation Metrics, Douglas W. Nishimura, Research Scientist, Image Permanence Institute, Rochester Institute of Technology, 2011.

33. Equilibrium Moisture Content of Wood in Outdoor Locations in the United States and Worldwide, William T. Simpson, Research Note FPL-RN-0268, United States Department of Agriculture, 1998.

34. L. Cirrincione, G. Peri, M. Pietrafesa, G. Rizzo, G. Scaccianoce, Suitability of Some Existing Damage Indexes for Regulating Contracts Between Curators of Museums and HVAC 
Maintenance and Management Companies, Proceedings of the $13^{\text {th }}$ SDEWES Conference, September 30 - October 4, Palermo, Italy $\left(13^{\text {th }}\right.$ Conference on Sustainable Development of Energy, Water and Environment Systems), 2018.

35. ASHRAE Handbook-HVAC Applications. Chapter 23: Museums, Galleries, Archives, and Libraries. American Society of Heating, Refrigerating and Air-Conditioning Engineers Inc., 2007. 